Mathematical Modelling and Analysis

Volume 5, 2000, PAGes 175-180

(C) 2000 Technika

\title{
THE ANALYSIS OF CHEMICAL KINETICS EQUATIONS WITH TIME DELAY
}

\author{
D. ŠVITRA ${ }^{1,2}$, R. RETKUTE் ${ }^{2}$ \\ ${ }^{1,2}$ Klaipèda University
}

H. Manto 84, LT-5800 Klaipeda, Lithuania

1 Institute of Mathematics and Informatics

Akademijos 4, Vilnius, Lithuania

E-mail: renret@ip.ku.lt

Received October 4, 1999; revised November 2, 1999

\begin{abstract}
The stability analysis of one mathematical model of isolated population is given. The delays have been incorporated into equations.
\end{abstract}

\section{FORMULATION OF THE PROBLEM}

The isolated population is an object of our studies. Let $N(t)$ be the size of population at the time $t$. In this case the growth of population is described by the equation:

$$
N^{\prime}(t)=\lambda(N(t))-\beta N(t),
$$

there $\lambda(N(t))$ is the speed of growth and $\beta N(t)$ is the speed of death.

Mono in 1942 had suggested, that the form of $\lambda(N(t))$ must be:

$$
\lambda(N)=\alpha \frac{N}{1+N^{n}} .
$$

The equation (1.2) was used for the first time to describe reactions of chemical kinetic by Michaelis and Mentin [2].

In comparison with chemical systems, biological systems are of extreme complexity. The time needed for feedback connections may be of considerable length. Thus delays have to be incorporated into models equations. 
The dynamics of isolated population is described by difference-differential equations:

$$
\begin{aligned}
& N^{\prime}(t)=\alpha \frac{N(t-h)}{1+\left(\frac{N(t-h)}{K}\right)^{n}}-\beta N(t), \\
& N^{\prime}(t)=\left(\alpha \frac{1}{1+\left(\frac{N(t-h)}{K}\right)^{n}}-\beta\right) N(t) .
\end{aligned}
$$

We present the basic properties of equation (1.3.)

1. If the following condition is satisfied:

$$
\lim _{t \rightarrow \infty}, N(t) \leq \frac{\alpha}{\beta n} K(n-1)^{1-\frac{1}{n}}
$$

then the solution of (1.3) is stable and converges to the steady state monotonically.

2. The convergence

$$
N(t) \underset{t \rightarrow \infty}{\rightarrow} K \sqrt[n]{\frac{\alpha}{\beta}-1}
$$

follows in two ways:

1) monotonically, if

$$
0<\frac{(\alpha-\beta) \beta n}{\alpha}-\beta \leq \frac{1}{h e^{1+\beta h}},
$$

2) oscillating around the nontrivial steady state, if

$$
\frac{1}{h e^{1+\beta h}}<\frac{(\alpha-\beta) \beta n}{\alpha}-\beta \leq \sqrt{\left(\frac{w_{*}}{h}\right)^{2}+\beta^{2}},
$$

where the number $w_{*}$ denotes the solution of the equation

$$
-\frac{1}{\beta h} w=t g w
$$

in the interval $(0 ; \pi)$.

3. The differential-difference equation (1.3) has non-constant periodic solutions.

4. The solutions of (1.3) can behave chaotically.

These properties are investigated in [1]. 


\section{THE BASIC PROPERTIES OF EQUATION (1.4}

In this section we consider equation (1.4).

Theorem 2.1. The solution of (1.4) is stable and converges to the steady state

$$
N=K \sqrt[n]{\frac{\alpha-\beta}{\beta}}
$$

monotonically, if the following condition is satisfied:

$$
0<\frac{(\alpha-\beta) \beta n}{\alpha} \leq \frac{1}{e h}
$$

Proof. The characteristic quasipolynomial, which is associated with the approximation of (1.4) in a neighbourhood of the nontrivial steady state has a form:

$$
P(\lambda)=\lambda+\frac{[\alpha-\beta] \beta n}{\alpha} e^{-h \lambda}=0 .
$$

The solution of (1.4) will be asymptotically stable if roots of (2.2) will be real and negative. Let

$$
a=\frac{(\alpha-\beta) \beta n}{\alpha}
$$

then

$$
\lambda+a e^{-\lambda h}=0 .
$$

The solution of (2.3) is obtained as a point of intersection of two functions: $y=-\lambda$ and $y=a e^{-\lambda h}$. These functions intersect if,

$$
0<a \leq \frac{1}{e h} \quad 0<\frac{(\alpha-\beta) \beta n}{\alpha} \leq \frac{1}{e h}
$$

Theorem 2.2. The solution of (1.4) is stable and converges to the steady state 2.1 oscillating, if the following conditions are satisfied:

$$
\begin{aligned}
& \alpha-\beta>0, \\
& \frac{1}{e h}<\frac{(\alpha-\beta) \beta n}{\alpha} \leq \frac{\pi}{2 h} .
\end{aligned}
$$

Proof. The characteristic quasipolynomial associated with the approximation of (1.4) in a neighbourhood of the nontrivial steady state has a form (2.2). For $\lambda=i w$ the real part of the function

$$
H(\lambda) \equiv P(\lambda) e^{\lambda h}=\lambda e^{\lambda h}+\frac{(\alpha-\beta) \beta n}{\alpha}
$$


is given by

$$
F(w) \equiv \operatorname{Re} H(i w)=-w \sin w h+\frac{(\alpha-\beta) \beta n}{\alpha},
$$

and its imaginary part is given by

$$
G(w) \equiv \operatorname{Im} H(i w)=w \cos w h
$$

According to the theorem of Ponrtjagin and Chebotariov (see Bellman and Cook [5], Chap. 13) the transcendental function $H(\lambda)$ has all its zeros on the left of the imaginary axis if and only if all zeros of the function $G$ are real and satisfy the inequality:

$$
G^{\prime}(\lambda) F(\lambda)>0 .
$$

Zeros of G satisfy the equation

$$
w \cos w h=0 .
$$

The solutions of (2.5) are $y=0$ and $y_{k}=\frac{\pi}{2 h}+\frac{\pi k}{h}, k=0, \pm 1, \ldots$. All zeros of $G$ are real. The derivative of the $G$ has a form:

$$
G^{\prime}(w)=\cos w h-w h \sin w h
$$

For $w_{0}=0$ :

$$
G^{\prime}(0) F(0)=\frac{(\alpha-\beta) \beta n}{\alpha}>0, \quad \alpha>\beta .
$$

The proof will be completed if (2.4) is proved to be a necessary and sufficient condition for

$$
G^{\prime}\left(w_{k}\right) F\left(w_{k}\right)>0 .
$$

For both negative and positive odd indexes $w_{k}=w_{2 m+1}=\frac{\pi}{2 h}+\frac{(2 m+1) \pi}{h}$,

$$
\begin{gathered}
\cos w_{2 m+1} h=\cos \left(\frac{\pi}{2}+(2 m+1) \pi\right)=0, \\
\sin w_{2 m+1} h=\sin \left(\frac{\pi}{2}+(2 m+1) \pi\right)=-1 .
\end{gathered}
$$

It follows that

$$
\begin{aligned}
G^{\prime}\left(w_{2 m+1}\right) F\left(w_{2 m+1}\right)= & \left(\frac{\pi}{2}+2 m \pi\right) \times \\
& \left(\frac{(\alpha-\beta) \beta n}{\alpha}+\left(\frac{\pi}{2 h}+\frac{(2 m+1) \pi}{h}\right)\right)>0 .
\end{aligned}
$$


The member in the first brackets is positive, so we obtain, that condition (9) is satisfied if

$$
-\frac{(\alpha-\beta) \beta n}{h}<\frac{\pi}{2 h}+\frac{(2 m+1) \pi}{h} .
$$

In the following let $k$ be an even number: $w_{k}=w_{2 m}=\frac{\pi}{2 h}+2 m \pi$. Then

$$
\begin{gathered}
\cos w_{2 m} h=\cos \left(\frac{\pi}{2}+2 m \pi\right)=0 \\
\sin w_{2 m} h=\sin \left(\frac{\pi}{2}+2 m \pi\right)=1 \\
G^{\prime}\left(w_{2 m}\right) F\left(w_{2 m}\right)=-\left(\frac{\pi}{2}+2 m \pi\right)\left(\frac{(\alpha-\beta) \beta n}{\alpha}-\left(\frac{\pi}{2 h}+\frac{2 m \pi}{h}\right)\right)>0 .
\end{gathered}
$$

The member in the first brackets is positive, so we obtain, that condition (2.6) is satisfied if

$$
\frac{(\alpha-\beta) \beta n}{\alpha}<\frac{\pi}{2 h}+\frac{2 m \pi}{h}
$$

Condition (2.7) is a partial case of condition (2.8). Clearly the sequence $\left(\frac{\pi}{2 h}+\frac{k \pi}{h}\right), k=0,1,2, \ldots$ is monotone increasing and it is necessary and sufficient for condition (2.6) to hold that

$$
\frac{(\alpha-\beta) \beta n}{\alpha}<\frac{\pi}{2 h}
$$

Comparing this result with the result of Theorem 2.1, we get, that the characteristic quasipolynomial of (1.4) in a neighbourhood of the nontrivial steady state has complex roots with negative real parts and nonzero imaginary parts, if

$$
\frac{1}{e h}<\frac{(\alpha-\beta) \beta n}{\alpha} \leq \frac{\pi}{2 h}
$$

We state our last result.

Theorem 2.3. If $0<\alpha-\alpha_{0}=\varepsilon \ll 1$ where

$$
\alpha_{0}=\frac{\beta^{2} n}{\beta n-\frac{\pi}{2}}
$$

then the bifurcating periodic solution of (1.4) has a form:

$$
N(t)=K \sqrt[n]{\frac{\alpha-\beta}{\beta}}+\zeta \cos \left(\frac{\pi}{2} h t\right)+\zeta^{2} x_{2}(t)+O\left(\zeta^{3}\right),
$$

where $\zeta, x_{2}(t)$ are calculated using bifurcation theory [3]. 


\section{REFERENCES}

[1] D. Švitra and R. Retkutè. Modifikuotos Mono lygties analizè. In: LMD mokslo darbai, vol.3, Technika, Vilnius, 1999.(submited)

[2] D. Švitra, R. Retkutè. Kraujodaros kamieniniụ lasteliụ dinamika. In: LMD mokslo darbai, vol.2, Technika, Vilnius, 1998, 326-333.

[3] D. Švitra. Dinamika fiziologiceskich sistem. Mokslas, Vilnius, 1989. (in Russian)

[4] R. Bellman, K.L. Cook. Differential-Difference Equations. Acad. Press, New York-San Francisco-London, 1963.

\section{CHEMINĖS KINETIKOS LYGČIŲ SU VE்LUOJANČIU ARGUMENTU ANALIZE்}

D. S̆VITRA, R. RETKUTE்

Nagrinëjama atskiros populiacijos matematinio modelio asimptotika. Ji remiasi charakteringojo kvazipolinomo šaknų analize. Surastos sąlygos, kada sprendinys artejja prie stacionaraus taško monotoniškai, osciliuodamas. Suformuluota teorema apie bifurkacijos taškus. 